\title{
Breastfeeding Videos as a New Training Tool for Malaysian Breastfeeding Peer Counsellor Program in Empowering Breastfeeding Communities
}

\author{
Ezura Madiana Md Monoto ${ }^{1}$, Nor Kamariah Mohamad Alwi². \\ ${ }^{1}$ Department of Family Medicine, UKM Medical Centre, Universiti Kebangsaan Malaysia, ${ }^{2}$ Susuibu.com, Bandar \\ Baru Bangi Selangor, Malaysia.
}

\begin{abstract}
The Malaysian Breastfeeding Peer Counsellors (MBFPC) is the pioneer of non-governmental organization (NGO) of trained breastfeeding peer counsellors in Malaysia initiated in 2010. The training was done in a systematic way using a developed syllabus that was adapted from and endorsed by the La Leche League International (LLLI) to suit our local population. Training materials used throughout the program were presentation slides, demonstration tools, mantas and role-plays. Materials and methods: In 2015, MBFPC partnered with Global Health Media Project (GHMP) to incorporate breastfeeding videos as training tool to further enhance the delivery of current breastfeeding peer counsellor trainings to the participants, emphasizing on helping breastfeeding mothers. The new training tool was evaluated in 38 participants, who underwent 21 hours of training. Participants were required to do pre and post-assessments to complete the MBFPC Modules, view 8 videos and do practical sessions within a 2 month period post training. Participants' field experience survey and focus group discussions were conducted among the participants and the trainers to look at the practicality of the videos in our training. Results: All participants felt that the videos made the training more effective and helped change their understanding and approach. The trainers agreed that the videos had covered all key topics need to be delivered in the training modules and helped them to deliver most important topics in helping breastfeeding mothers in a more practical way. Conclusion: GHMP Breastfeeding Videos are suitable as educational and training tools in helping breastfeeding mothers in our training.
\end{abstract}

KEYWORDS: breastfeeding, peer counsellor, training tool

\section{INTRODUCTION}

Mother-to-Mother Support has been identified as one of the factors contributing to the success rate of prolonged breastfeeding, or at least exclusive breastfeeding in the first 6 months of life. A 2007 Cochrane review of breastfeeding promotion programs indicated that lay support (trained nonprofessionals) who may or may not share the same socioeconomic and cultural background is effective in increasing breastfeeding duration and that the benefits increase to exclusive breastfeeding more than to any breastfeeding. ${ }^{1}$ Local community women who have experienced breastfeeding success, are trained to become breastfeeding peer counsellors to work with women of similar culture, demographic and socioeconomic background to promote positive breastfeeding outcomes. ${ }^{2}$

In Malaysia particularly, there is a continual drive to create a more functional Mother-to-Mother Support Group framework among mothers. Many mothers are interested to participate in these activities and are willing to support each other. To fill in the gaps, some mothers had joined the breastfeeding training available in the hospital. However, hospital training may not be $100 \%$ relevant to mother-to-mother support needs. The current WHO/UNICEF 20-hours Lactation Management Training and the 40-hours

Ezura Madiana Md Monoto, Department of Family Medicine,

UKM Medical Centre,Universiti Kebangsaan Malaysia, Jalan Yaacob Latiff, 56000, Kuala Lumpur, Malaysia. Email: ezura@ppukm.ukm.edu.my
Breastfeeding Counselling Course for Health Professionals are conducted in the hospitals mainly to train the health professionals with medical background.As such, mothers who had undergone these training may not receive proper guidelines on how to operate as peer counsellors. In response to this need, the Breastfeeding Peer Counsellor Training Module was introduced in Malaysia in January 2010. Initially based on the La Leche League International Breastfeeding Peer Counsellor Program, the module was then adapted, updated and published in May 2010 as the Malaysian Breastfeeding Peer Counsellor (MBFPC) Program Module, and became the pioneer of a structured breastfeeding peer counsellor program in Malaysia. The module focuses on communications skills for the peer counsellor, breastfeeding anatomy, physiology and human milk composition, basic breastfeeding management, barriers that confront breastfeeding mothers, understanding baby's needs from infancy to toddlerhood and breastfeeding in situations of a medical nature. These topics were delivered via presentation slides, demonstration tools, mantas (posters on piece of cloths) and role-play.

The initial phase of the project, which includes training of the Peer Counsellor Program Administrator and potential peer counsellors in 5 regions in Malaysia (North, South, Central, East Coast and East Malaysia) was made possible with the funding from The United Nation Children's Fund (UNICEF) and supported by World Alliance for Breastfeeding Action (WABA). By the end of 2010, a 
network of more than 100 peer counsellors had been established, who had volunteered to help with breastfeeding support and education in their respective communities, established nationwide. The numbers are expanding with on-going trainings. This network was referred to as the MBFPC. Among the activities run by MBFPC include one-to-one counselling, organizing mother-tomother and father-to-father support group meetings, breastfeeding support meetings at workplaces and hospitals, and participating in community exhibitions and awareness programs. Every year since then, 3 to 5 trainings sessions had been conducted in Malaysia based on demand from many different communities, either needing to establish their own breastfeeding support group, or to equip existing support group members with breastfeeding peer counselling skills. The MBFPC Association conducted all these trainings.

The trainings underwent continuous improvements, based on the outcomes, comments and feedbacks obtained from previous training sessions. The work plan for each upcoming training was then revised to suit the unique and dynamic requirements of each target group. However, the essence of the training, which focuses on communication skills for peer counsellors, remains as core of the training modules. The course of the training is limited to 3 days of face-to-face interactions between the trainees and the trainers, making it quite impossible to evaluate the skills and knowledge acquired by each participant after completing this training.

In 2015, the Global Health Media Project (GHMP), a non-profit organization that designs and produces video and animation to teach key healthcare practices for frontline health workers and families in low-resource settings, developed 8 breastfeeding videos; covering key topics aimed at helping breastfeeding mothers dealing with common breastfeeding challenges. MBFPC in a pilot project to improve its training has incorporated the video sets into MBFPC Training Module, with the aim of further enhancing the delivery of the current breastfeeding peer counsellor trainings to their clients. These videos should improve the knowledge and skills of the peer counsellors themselves as they work to assist breastfeeding mothers in the community.

\section{MATERIALS AND METHODS}

In the recent training which started in 2015, the GHMP videos were introduced during sessions along with the current training materials and methods as a new visual tool to better illustrate certain topics related to the modules covered. The videos include; Early Initiation of Breastfeeding, Helping a Breastfeeding Mother, Breastfeeding Positions, Breastfeeding Attachment, Nipple Pain, Breast Pain, Not Enough Milk, and Expressing Breast Milk. To evaluate this new tool as part of our training method, we conducted a pilot study where 38 participants were recruited to undergo a 21-hour training over 3 days. The training included a baseline pre-assessment test, followed by didactic and hands-on training in accordance to the MBFPC Training Module, along with the new 8 GHMP videos supplementing the module. A total of 4 trainers with International Board Certified Lactation Consultant (IBCLC) credentials conducted the training sessions. Following the training sessions, participants were required to go through a 2-month practical period of observing and helping at least 4 breastfeeding mothers. Participants were then gathered for postpractical assessment, participants' field experience survey and focus group discussion. During the training, 8 videos were downloaded onto each participants' mobile phones which were to be used as sharing tools with the mother they were helping during their practical session and/or as refresher tools for the participants to remember important points in helping breastfeeding mothers. Along with the videos, the Breastfeeding Observation Aid form was introduced, where during the practical period the participants were required to use the form to jot down their observation on each mother they were helping.

\section{RESULTS}

In this paper, we focused on the participants' field experience survey and focus group discussion to evaluate the practicality of the videos as a new training tool in our training module. 36 out of 38 participants returned for the post-practical assessment, participants' field experience survey and focus group discussion. The purpose of the participants' field experience survey was to find out regarding the usage of the breastfeeding videos when they visited the mothers during the practical sessions (Figure 1).

Figure 1. Participants' Field Experience Survey

\section{Survey on field experience since initial training}

1.Did you use the videos to review the information? Which videos? How many times?

2. How many birthing woman did you visit since your training in May?

3.Did you take your smartphone (or mobile device) with you when you visited mothers?

4.Did the mothers that you visited have specific issues or problems with breastfeeding?

5. Did you show the videos to the mothers? Which videos? How many times?

Based on the participants' field experience survey, the videos watched most frequently by the participants were Breastfeeding Positioning followed by Breastfeeding Attachment and Expressing Breastmilk; 83, 77 and 60 times respectively. The most common problems encountered during the 2month practical period were; poor attachment, mothers not being confident in their milk supply, inverted/flat/large nipples, nipple confusion and sore nipples. The videos that participants showed to mothers most often were; Breastfeeding Attachment, Breastfeeding Positioning and Expressing Breastmilk; 77, 60 and 50 times respectively (Table 1$)$. 
Table 1. Participants' responses on field experience survey

\begin{tabular}{|c|c|c|c|c|c|}
\hline & Q1 & Q2 & Q3 & Q4 & Q5 \\
\hline 1 & Yes. Latching and Hand Expression & 4 & Yes & Yes & Yes. Latching \\
\hline 2 & $\begin{array}{l}\text { Yes. Expressing breastmilk, attach- } \\
\text { ment }\end{array}$ & 3 & Yes & $\begin{array}{l}\text { Latching problem due to used to } \\
\text { bottle feeding }\end{array}$ & $\begin{array}{l}\text { Yes. Attachment, expressing breast- } \\
\text { milk - } 3 \text { times }\end{array}$ \\
\hline 3 & $\begin{array}{l}\text { Yes. Hand Express, Latching and En- } \\
\text { gorgement. Several times }\end{array}$ & 16 & Yes & $\begin{array}{l}\text { Sore/cracked nipple, poor at- } \\
\text { tachment. Blocked } \\
\text { ducts/engorgement }\end{array}$ & \\
\hline 4 & $\begin{array}{l}\text { Yes. Early initiation(2), Attach- } \\
\text { ment(8), Positioning(8), Not enough } \\
\text { milk(8), Breast pain (2), Expression(6) }\end{array}$ & 4 & Yes & Yes & $\begin{array}{l}\text { Yes. } \\
\text { (Attachment(4), Position(4), Not } \\
\text { enough milk(3), breastpain(2), } \\
\text { nipple pain(2), Expression(2) }\end{array}$ \\
\hline 5 & Yes. Not enough milk. & 4 & Yes & $\begin{array}{l}\text { Yes. Not enough milk. Refuse to } \\
\text { latch }\end{array}$ & Yes. Not enough milk. Once \\
\hline 6 & $\begin{array}{l}\text { Yes. Attachment, Positioning, Expres- } \\
\text { sion, Many times }\end{array}$ & 3 & Yes & (actir & $\begin{array}{l}\text { Attachment, Position, Expression- } \\
\text { every visit }\end{array}$ \\
\hline 7 & $\begin{array}{l}\text { Yes. Positioning, Nipple Pain, Express } \\
\text { breastmilk }\end{array}$ & 4 & Yes & Yes. Nipple pain, mastitis & $\begin{array}{l}\text { Yes. Positioning, Nipple Pain, Ex- } \\
\text { press breastmilk (1-2 times) }\end{array}$ \\
\hline 8 & $\begin{array}{l}\text { Yes. Attachment, Not enough milk, } \\
\text { Expressing breastmilk. Few times }\end{array}$ & 4 & Yes & $\begin{array}{l}\text { Latching, breast abscess, outside } \\
\text { interference }\end{array}$ & No \\
\hline 9 & Yes. All videos. 1-2 times & 5 & Yes & Positioning & Yes. Attachment. 2-3 times \\
\hline 10 & $\begin{array}{l}\text { Yes. Attachment and Position. 4-5 } \\
\text { times }\end{array}$ & 4 & Yes & $\begin{array}{l}\text { Yes. Baby jaundice, nipple pain, } \\
\text { nipple confusion, baby eczema }\end{array}$ & $\begin{array}{l}\text { Yes. Nipple pain, attachment and } \\
\text { position. } 4 \text { times }\end{array}$ \\
\hline 11 & Yes. Review each video 1-3 times & 4 & Yes & $\begin{array}{l}\text { Yes. Cracked nipple, engorge- } \\
\text { ment, not enough milk }\end{array}$ & Attachment (4), \\
\hline 12 & $\begin{array}{l}\text { Yes. Attachment, Breast Pain, Posi- } \\
\text { tioning. } 2 \text { times }\end{array}$ & 4 & Yes & Not All & $\begin{array}{l}\text { Yes. Attachment, Breast Pain. } 2 \\
\text { times }\end{array}$ \\
\hline 13 & $\begin{array}{l}\text { Yes. Breast pain, not enough milk. } 4 \\
\text { times }\end{array}$ & 4 & Yes & No. & Yes. All videos. 1-2 times \\
\hline 14 & Yes. Positioning. 6 times & 12 & Yes & $\begin{array}{l}\text { Yes. Attachment, positioning, } \\
\text { crack nipple }\end{array}$ & $\begin{array}{l}\text { Yes. Position (4), Nipple } \\
\text { Pain(2),Express breastmilk(1) }\end{array}$ \\
\hline 15 & $\begin{array}{l}\text { Yes. Positioning and hand expression. } \\
4 \text { times }\end{array}$ & 4 & Yes & (2) & Yes. Positioning. 2 times. \\
\hline 16 & Yes. All videos. & 4 & Yes & $\begin{array}{l}\text { Yes. Not enough milk, inverted } \\
\text { nipple, poor attachment }\end{array}$ & $\begin{array}{l}\text { Yes. Attachment, Positioning, not } \\
\text { enough milk }\end{array}$ \\
\hline 17 & Yes. All. 1 time & 4 & Yes & $\begin{array}{l}\text { Yes. Let down too fast, Engorge- } \\
\text { ment, Nipple sore }\end{array}$ & $\begin{array}{l}\text { Engorgement (2), Hand express(2), } \\
\text { Early initiation (1) }\end{array}$ \\
\hline 18 & $\begin{array}{l}\text { Yes. Attachment, nipple pain. 3-4 } \\
\text { times }\end{array}$ & 4 & Yes & $\begin{array}{l}\text { Yes. Inverted nipple, premature } \\
\text { baby, breast refusal }\end{array}$ & Yes. Early initiation, attachment \\
\hline 19 & $\begin{array}{l}\text { Yes. Not enough milk, position, hand } \\
\text { express }\end{array}$ & 4 & Yes & $\begin{array}{l}\text { Not confident, no milk, using } \\
\text { pump in early days. Positioning }\end{array}$ & $\begin{array}{l}\text { Yes. Positioning, Not enough milk, } \\
\text { hand express }\end{array}$ \\
\hline 20 & $\begin{array}{l}\text { Yes. Attachment, Positioning, Early } \\
\text { Initiation, Expressing. 5-6 times }\end{array}$ & 5 & Yes & $\begin{array}{l}\text { Yes. Sore Nipple, Inverted nipple, } \\
\text { nipple confusion }\end{array}$ & $\begin{array}{l}\text { Yes. Attachment, Positioning, ex- } \\
\text { pressing ( } 2-3 \text { times) }\end{array}$ \\
\hline 21 & Yes. All videos. More than $5 \mathrm{x}$. & 4 & Yes & $\begin{array}{l}\text { Position and attachment, flat } \\
\text { nipple }\end{array}$ & $\begin{array}{l}\text { Yes. Positioning, expressing breast- } \\
\text { milk, nipple pain, attachment. } 2 \\
\text { times }\end{array}$ \\
\hline 22 & $\begin{array}{l}\text { Yes. Position }-4 X \text {, breast pain }-2 x, \\
\text { Early initiation } 2 X\end{array}$ & 4 & Yes & $\begin{array}{l}\text { Poor attachment, suckling prob- } \\
\text { lem, poor milk supply }\end{array}$ & Yes. Attachment - 1 time \\
\hline 23 & Yes. All videos. 2 times & 4 & Yes & 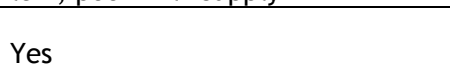 & $\begin{array}{l}\text { Yes. Attachment and position. Both } \\
1 \text { time }\end{array}$ \\
\hline 24 & $\begin{array}{l}\text { Yes. Position, Attachment, Nipple } \\
\text { Pain }\end{array}$ & 4 & Yes & Sore nipple. Low Milk Supply. & Yes. Attachment \\
\hline 25 & Yes. All videos. 1-2 times & 1 & Yes & No & No \\
\hline 26 & Yes. Attachment, positioning, 2 times & 4 & Yes & $\begin{array}{l}\text { Yes. Shallow latch, nipple pain, } \\
\text { baby refuse to latch, worry of } \\
\text { not enough milk }\end{array}$ & $\begin{array}{l}\text { Yes. Attachment \& positioning. } 2 \\
\text { times }\end{array}$ \\
\hline 27 & Yes. All video. More than $4 \mathrm{x}$ & 4 & Yes & Yes & $\begin{array}{l}\text { Yes. Breast Pain \& Attachment. } \\
\text { More than } 4 \text { times }\end{array}$ \\
\hline 28 & $\begin{array}{l}\text { Yes. Attachment(4), Hand Expres- } \\
\text { sion(2), Positioning ( } 3 \text { ) }\end{array}$ & 4 & Yes & Yes & $\begin{array}{l}\text { Yes. Attachment(4), Hand Expres- } \\
\text { sion(2), Positioning ( } 3 \text { ) }\end{array}$ \\
\hline 29 & Yes. All videos. & 4 & Yes & $\begin{array}{l}\text { Yes. Breast pain, latching tech- } \\
\text { nique }\end{array}$ & Yes. Breast pain, attachment \\
\hline 30 & $\begin{array}{l}\text { Yes. Attachment, positioning, breast } \\
\text { pain, expressing breastmilk. More } \\
\text { than } 10 \text { times }\end{array}$ & 15 & Yes & $\begin{array}{l}\text { Nipple sore, engorgement, nipple } \\
\text { confusion, latching problem }\end{array}$ & $\begin{array}{l}\text { Yes. Attachment. Positioning, Ex- } \\
\text { press breastmilk ( } 25 \text { times) }\end{array}$ \\
\hline 31 & Yes. All videos. More than 5 times & 4 & Yes & $\begin{array}{l}\text { Inverted nipple, difficult to } \\
\text { latch, nipple confusion }\end{array}$ & $\begin{array}{l}\text { Yes. Attachment (5), Positioning } \\
\text { (4), Hand Express(2), Early Initia- } \\
\text { tion( } 2 \text { ), Not Enough milk (3) }\end{array}$ \\
\hline 32 & Yes & 2 & Yes & Yes. Some of them & Yes. Expressing Milk. 1 time \\
\hline 33 & Yes. Early Initiation. 2 times & 4 & Yes & Yes & $\begin{array}{l}\text { Yes. Engorgement, Hand Expression. } \\
1-2 \text { times }\end{array}$ \\
\hline 34 & $\begin{array}{l}\text { Yes. Attachment and positioning. } \\
\text { More than } 4 \text { times }\end{array}$ & 4 & Yes & $\begin{array}{l}\text { Yes. Nipple confusion, large nip- } \\
\text { ple, jaundice and sleepy baby, } \\
\text { not confident in her milk supply }\end{array}$ & Yes. Attachment and positioning. \\
\hline 35 & Yes. & 5 & Yes & Yes & Hand Expression. $1-2$ times \\
\hline 36 & $\begin{array}{l}\text { Yes. Attachment (4), Positioning(2), } \\
\text { Hand Expression(1), Others(1-2) }\end{array}$ & 2 & Yes & Yes & Yes. Attachment. 1 time \\
\hline
\end{tabular}


All of the participants reported bringing their smartphones with them for the visits. The mothers they visited had various breastfeeding-related issues. 33 showed the videos to the mothers and 23 of them showed more than one video. Breastfeeding Attachment and Breastfeeding Positioning were the most frequently shown videos and reportedly the most useful by the participants. In the focus group discussion among the participants, the topics discussed were to find out whether the videos made the training more effective, how did the videos help trainees learn and how did the videos help them do their job better. All participants felt that the videos made the training more effective and reported that GHMP videos are more detailed and easy to understand. They also reported that the videos helped change their understanding and approach. The videos reported to work best in teaching about practice and how to guide other mothers are Breastfeeding Positioning, Breastfeeding Attachment and Hand Expression.

The participants also reported to have review the videos a few times after the training, especially watching relevant videos just before visiting and helping a breastfeeding mother. It helped them to remember the key points while helping the mothers. During the training, there were a lots of 'Aha' moments experienced by the participants while watching the videos. Among the reason of some of them never seen it in practice but rather reading it from textbooks. Among the videos that triggered the 'Aha' moments for them were Milk Expression. It made them realize that hand expression may resulted in better yield in expressing the milk.

Most mothers that they shared the video with were impressed with the videos that they wanted to share them with other mothers too. Most mothers that watched the videos had improved their practices and can feel the change in the outcomes after a few days. Among the experiences that have been improved are better attachment, better positioning, better yield during hand expression and less pain during feeding session.

In the focus group discussion among the trainers, the goal is to find out if the videos made it easier to teach and conduct the training, did it lead to better results and did it help the participants understand and learn the material. All trainers agreed that the videos had covered all key topics need to be delivered in the training modules. Among the videos that work best in the teaching experience were the Breastfeeding Attachment, Expressing Breastmilk and Helping a Breastfeeding Mother.

On the length of the videos, all trainers agreed that 8-10 minutes length of the videos are just right for the purpose of training. Shorter video may be more suitable for sharing among mothers. Most of the videos triggered a lot of 'Aha' moments among the participants during the training. The trainers felt that the participants had the 'Aha' moments since it was the first time they saw such scenes, having previously only read about it in textbooks.
Regarding video usage in breastfeeding training, GHMP videos are not the first one. In the beginning, the trainers felt the GHMP videos may look very long as previously all videos used in the training are short clips to make sure participants can retain their focus in watching the video. However, after experiencing using GHMP videos, the chronology shown in the lengthy video is important and helps the trainees to understand the full picture on breastfeeding issues and practice.

Introducing the video in the MBFPC training was timely, as the trainers were looking forward to any new tools they can use to enhance their methods of training. The videos have helped the trainers to deliver most important topics in helping breastfeeding mothers in a more practical way.

\section{DISCUSSION}

The overall quality of the video is suitable for training purposes. All participants and trainers agreed that the videos were easy to be used and understood. Having the videos as part of the training tools help the trainers to deliver the content of the modules in a more efficient way. Less demonstrations were need and it was easy to capture participants' attention on the topic discussed. The videos concluded each topic well especially with the element of 'take home messages' points at the end of each video.

The videos come in handy for reviewing and sharing as they were downloaded to the participants' smartphones. They were able to watch relevant videos for as many times as needed to better understand the topics they were not clear during the training. It empowered them to gain knowledge and confidence in supporting other mothers in their communities to improve their breastfeeding experiences.

Breastfeeding peer counsellor support and sharing relevant breastfeeding videos with the mothers according to their individual needs may help in improving their breastfeeding practices and may help new mothers to breastfeed for a longer duration and sustain exclusive breastfeeding for at least 6 months postpartum. As compared to screening of breastfeeding educational video in the prenatal clinic for at-risk pregnant women during third trimester, it may not be enough to influence the initiation and exclusivity of breastfeeding during the hospital stay and a multifaceted approach are required to achieve this.

Interventions such as peer counselling and breastfeeding videos or combination of both were found to be effective in initiating and continuing breastfeeding postpartum.Breastfeeding videos could be shared to support mothers and help to deliver the message and understand the concepts and techniques better.

Although some videos were quite lengthy and may 
not be suitable for mothers who are in difficulties to watch them fully, they can always refer to the videos again and watch them at their preferred time to ensure that the important messages in the video are not missed. It is also recommended that if some of the videos can be divided into few shorter videos to preserve the attention span of the mother. The videos will also be most suitable to be incorporated in other breastfeeding training especially involving health care personnel as they may have more opportunity to practice most of the topics covered in the video series.

\section{CONCLUSION}

The evolution of this project with the new training tool has shown that GHMP Breastfeeding Videos are suitable as education and training tools. It has further improved the training method in delivering the content of the modules in a more efficient way.

\section{ACKNOWLEDGEMENTS}

Authors would like to thank The Global Health Media Project (GHMP) for funding this study and training of 38 participants, and the Dean and Director of Hospital Canselor Tuanku Muhriz, Universiti Kebangsaan Malaysia Medical Centre for the support given.

\section{REFERENCES}

1. Britton C, McCormick FM, Renfrew MJ, Wade A, King SE. Support for breastfeeding mothers. Cochrane Database of Systematic Reviews 2007. Cochrane Database Syst Rev. 2007;(1)

2. Chapman DJ, Damio G, Young S, Pérez-Escamilla R. Effectiveness of breastfeeding peer counseling in a low-income, predominantly Latina population: a randomized controlled trial. Arch Pediatr Adolesc Med. 2004;158(9):897-902.

3. World Health Organization, UNICEF Breastfeeding counselling: training course, Trainer's guide, 1993, Geneva, World Health Organization

4. Global Health Media Project. Global Health Media Breastfeeding Videos [Internet]. [cited 20/09/2016]. Available from: http://globalhealthmedia.org/videos/breastfeed ing/

5. World Health Organization U. BFHI Section 3: Breastfeeding Promotion and Support in a Babyfriendly Hospital, a 20-hour course for maternity staff. In: World Health Organization U, editor. Baby-friendly hospital initiative : revised, updated and expanded for integrated care.. WHO Press; 2009. p. 120.

6. Sudfeld CR, Fawzi WW, Lahariya C, Amre D. Peer support and exclusive breastfeeding duration in low and middle-income countries: a systematic review and meta-analysis. PloS one. 2012;7(9):e45143.

7. Long DG, Funk-Archuleta MA, Geiger CJ, Mozar AJ, Heins JN. Peer Counselor Program Increases Breastfeeding Rates in Utah Native American
WIC Population. Journal of Human Lactation. 1995;11(4):279-84.

8. Kellams AL, Gurka KK, Hornsby PP, Drake E, Riffon M, Gellerson D, Gulati G, Coleman V. The impact of a prenatal education video on rates of breastfeeding initiation and exclusivity during the newborn hospital stay in a low-income population. Journal of Human Lactation. 2016 Feb;32(1):152-9.

9. Caulfield LE, Gross SM, Bentley ME, Bronner Y, Kessler L, Jensen J, Weathers B, Paige DM. WICbased interventions to promote breastfeeding among African-American Women in Baltimore: effects on breastfeeding initiation and continuation. Journal of Human Lactation. 1998 Mar;14(1):15-22. 